\title{
Perfil dos autores premiados na categoria Romance do Prêmio Jabuti
}

\author{
Profile of the authors awarded in the \\ novel category of the Prêmio Jabuti
}

Ana Paula Teixeira Porto ${ }^{1}$

Emanoeli Ballin Picolotto ${ }^{2}$

\begin{abstract}
Resumo: Com seu surgimento em 1958, o Prêmio Jabuti busca agraciar obras de autores brasileiros nas diferentes áreas do conhecimento e consiste no principal prêmio de literatura no Brasil. Assim, por sua grande abrangência e prestígio, tanto dentro como fora do Brasil, merece pesquisas e reflexões no meio acadêmico. Desse modo, este trabalho tem como objetivo apresentar uma breve descrição sobre essa premiação e, em seguida, identificar o perfil dos autores premiados no século XXI, entre os anos 2000 e 2016, apenas na categoria romance. Ao se realizar a investigação de cunho bibliográfico, constata-se que o Prêmio Jabuti está dando enfoque a autores iniciantes ou não na literatura, que vivem no eixo Rio-São Paulo e, na maioria, do sexo masculino, brancos, com formação qualificada e, em grande parte, relacionada às letras.

Palavras-chave: Prêmio Jabuti. Romances do século XXI. Perfil de autores.

Abstract: With its appearance in 1958, the Prêmio Jabuti seeks to award works by Brazilian authors in the different areas of knowledge and consists of the main literature prize in Brazil. Thus, due to its wide range and prestige both inside and outside Brazil, it deserves research and reflection in the academic world. Thus, this paper aims to present a brief description of this award and then to identify the profile of these award-winning authors in the XXI century, between the years 2000 and 2016, only in the novel category. When the bibliographic research is carried out, it is verified that the Prêmio Jabuti is focusing on authors who are new or not in the literature, who live in the Rio-São Paulo axis, and authors in the majority of males and whites.
\end{abstract}

Keywords: Prêmio Jabuti. Novels of the 21st century. Profile of authors.

\section{Introdução}

Com o seu surgimento em 1958, o Prêmio Jabuti consiste no principal prêmio da literatura brasileira no Brasil e tem o objetivo de valorizar escritores e obras, conforme aponta a página do site oficial ${ }^{3}$. É reconhecido por sua grande abrangência, abarca diversas áreas do conhecimento (atualmente são 27 categorias analisadas) e, a cada nova edição, aumenta o número de inscritos.
Além disso, o autor que tiver a sua obra premiada em alguma modalidade e edição do Prêmio é reconhecido tanto dentro como fora do Brasil, assinalando a importância dessa avaliação enquanto instrumento de valorização de produção escrita, como indica a apresentação do site oficial do Prêmio:

É uma distinção que dá ao seu ganhador muito mais do que uma recompensa financeira. Ganhar o Jabuti representa dar à obra vencedora o lastro

\footnotetext{
1 Doutora e mestre em Letras. Professora dos Programas de Mestrado em Letras e Mestrado e Doutorado em Educação da Universidade Regional Integrada do Alto Uruguai e das Missões (URI). ORCID: http://orcid.org/oooo-0002-2674-8020. E-mail: anapaulateixeiraporto@gmail.com

2 Mestre em Letras pela Universidade Regional Integrada do Alto Uruguai e das Missões (URI). ORCID: https://orcid.org/oooo-ooo30881-9347. E-mail: emanoeli.ballinp@hotmail.com

3 As informações do site do Prêmio Jabuti são acessadas em http://premiojabuti.com.br/, fonte de consulta usadas neste artigo.
} 
da comunidade intelectual brasileira, significa ser admitido em uma seleção de notáveis da literatura nacional (CÂMARA BRASILEIRA DO LIVRO, [2017]).

Os principais fundadores do Prêmio Jabuti foram Edgar Cavalheiro e Mário da Silva Brito, estudiosos da literatura brasileira que tinham como principal objetivo premiar escritores, editores, ilustradores, gráficos e livreiros que se destacassem no decorrer do ano, buscando assim valorizar determinada obra. A origem do nome do Prêmio deu-se por uma homenagem ao escritor Monteiro Lobato que, assim como Sílvio Romero, Mário de Andrade e Luís Câmara Cascudo, na época, representavam em suas obras a cultura popular brasileira. Mas, dentre esses autores, Monteiro Lobato recebeu um destaque maior, pois foi contemplado com um de seus personagens mais famosos na identificação no Prêmio: Jabuti. Ele está presente na obra Reinações de Narizinho e possui como características ser vagaroso, mas, ao mesmo tempo, esperto e pronto para vencer obstáculos.

Com o passar dos anos, o Prêmio sofreu várias alterações. De acordo com o site do evento, o objetivo principal da CBL (Câmara Brasileira do Livro), que promove essa premiação, é o de abranger um número maior de pessoas, aperfeiçoar o espaço onde essa premiação acontece e ainda agregar categorias na concorrência, que no início possuía somente sete opções para que os autores se inscrevessem, sendo elas: literatura, capa e ilustração, editor, gráfico, livreiro e personalidade literária.

$\mathrm{O}$ número de autores interessados em ganhar o Jabuti cresceu gradativamente nos últimos anos. Isso pode ser explicado por várias razões, como a importância do Prêmio no cenário nacional, a ampliação das categorias de análise, divididas em obras de ficção e não ficção, e a premiação que, no caso da categoria romance, é de trinta e cinco mil reais para o vencedor de acordo com o regulamento da edição de 2016.

Além disso, é preciso considerar a visibilidade que o Prêmio dá ao autor e à obra. Em caso desse reconhecimento, seja como finalista ou como ganhador, é possível estimular ou obter uma mudança na carreira de escritor. Convites para eventos e feiras são algumas das consequências que esse sistema avaliativo pode trazer. Essa notoriedade também não fica restrita ao contexto brasileiro, pois se estende a projeções de autor e obra no exterior.

Partindo desses pressupostos iniciais o objetivo desse estudo é apresentar uma descrição pormenorizada do Prêmio Jabuti, desde a sua criação até a atualidade, considerando seus propósitos e regulamentos. Busca-se ainda, trazer apontamentos sobre qual o perfil de livro e de escritores que o Jabuti tem valorizado no século XXI a partir das tendências das premiações do período 2000-2016, considerando-se apenas a categoria romance, uma das 27 contempladas pelo Prêmio.

O recorte de análise de romances compreende apenas aqueles contemplados nas edições de 2000 a 2016 do Prêmio, pois nos interessamos em refletir sobre as relações entre essa literatura recente e a sua apreciação promovida através do Prêmio. Nesse sentido, no quadro 1, a seguir, é possível identificar quais são as obras que obtiveram a primeira colocação na categoria romance, seus autores e a editora correspondente, bem como o ano em que foram contempladas com o Prêmio Jabuti.

Quadro 1 - Rol de obras romanescas premiadas de 2000 a 2016

\begin{tabular}{|c|c|c|c|}
\hline $\begin{array}{c}\text { ANO DA } \\
\text { PREMIAÇÃ̃O }\end{array}$ & OBRA & AUTOR & EDITORA \\
\hline 2000 & $\begin{array}{c}\text { A Mulher que } \\
\text { escreveu a } \\
\text { Bíblia }\end{array}$ & $\begin{array}{l}\text { Moacyr } \\
\text { Scliar }\end{array}$ & $\begin{array}{l}\text { Cia. das } \\
\text { Letras }\end{array}$ \\
\hline 2001 & Dois Irmãos & $\begin{array}{l}\text { Milton } \\
\text { Hatoum }\end{array}$ & $\begin{array}{c}\text { Cia das } \\
\text { Letras }\end{array}$ \\
\hline 2002 & Barco a Seco & $\begin{array}{c}\text { Rubens } \\
\text { Figueiredo }\end{array}$ & $\begin{array}{c}\text { Cia das } \\
\text { Letras }\end{array}$ \\
\hline 2003 & Dias e Dias & $\begin{array}{c}\text { Ana } \\
\text { Miranda }\end{array}$ & $\begin{array}{c}\text { Cia das } \\
\text { Letras }\end{array}$ \\
\hline 2004 & Mongólia & $\begin{array}{l}\text { Bernardo } \\
\text { de } \\
\text { Carvalho }\end{array}$ & $\begin{array}{c}\text { Cia das } \\
\text { letras }\end{array}$ \\
\hline 2005 & $\begin{array}{l}\text { Vozes do } \\
\text { Deserto }\end{array}$ & $\begin{array}{l}\text { Nélida } \\
\text { Piñon }\end{array}$ & Record \\
\hline 2006 & $\begin{array}{c}\text { Cinzas do } \\
\text { Norte }\end{array}$ & $\begin{array}{l}\text { Milton } \\
\text { Hatoum }\end{array}$ & $\begin{array}{c}\text { Cia. Das } \\
\text { Letras }\end{array}$ \\
\hline
\end{tabular}




\begin{tabular}{|c|c|c|c|}
\hline $\begin{array}{c}\text { ANO DA } \\
\text { PREMIAÇÃO }\end{array}$ & OBRA & AUTOR & EDITORA \\
\hline 2007 & $\begin{array}{l}\text { A Vida que } \\
\text { Ninguém Vê }\end{array}$ & $\begin{array}{l}\text { Eliane } \\
\text { Brum }\end{array}$ & $\begin{array}{c}\text { Arquipélago } \\
\text { Editorial }\end{array}$ \\
\hline 2008 & O Filho Eterno & $\begin{array}{c}\text { Cristovão } \\
\text { Tezza }\end{array}$ & $\begin{array}{c}\text { Editora } \\
\text { Record } \\
\text { Ltda }\end{array}$ \\
\hline 2009 & $\begin{array}{l}\text { Manual } \\
\text { da Paixão } \\
\text { Solitária }\end{array}$ & $\begin{array}{l}\text { Moacyr } \\
\text { Scliar }\end{array}$ & $\begin{array}{l}\text { Cia das } \\
\text { Letras }\end{array}$ \\
\hline 2010 & $\begin{array}{c}\text { Se Eu Fechar } \\
\text { Os Olhos } \\
\text { Agora }\end{array}$ & $\begin{array}{l}\text { Edney } \\
\text { Silvestre }\end{array}$ & Record \\
\hline 2011 & Ribamar & $\begin{array}{c}\text { José } \\
\text { Castello }\end{array}$ & $\begin{array}{c}\text { Bertrand } \\
\text { Brasil }\end{array}$ \\
\hline 2012 & Nihonjin & $\begin{array}{c}\text { Oscar } \\
\text { Nakasato }\end{array}$ & $\begin{array}{c}\text { FGV } \\
\text { Direito }\end{array}$ \\
\hline 2013 & $\begin{array}{l}\text { O Mendigo que } \\
\text { Sabia de Cor } \\
\text { os Adágios } \\
\text { de Erasmo de } \\
\text { Rotterdam }\end{array}$ & $\begin{array}{l}\text { Evandro } \\
\text { Affonso } \\
\text { Ferreira }\end{array}$ & $\begin{array}{l}\text { Editora } \\
\text { Record }\end{array}$ \\
\hline 2014 & Reprodução & $\begin{array}{l}\text { Bernardo } \\
\text { Carvalho }\end{array}$ & $\begin{array}{c}\text { Companhia } \\
\text { das Letras }\end{array}$ \\
\hline 2015 & Quarenta Dias & $\begin{array}{c}\text { Maria } \\
\text { Valéria } \\
\text { Rezende }\end{array}$ & $\begin{array}{c}\text { Editora } \\
\text { Objetiva }\end{array}$ \\
\hline 2016 & A Resistência & $\begin{array}{l}\text { Julián } \\
\text { Fuks }\end{array}$ & $\begin{array}{l}\text { Companhia } \\
\text { das Letras }\end{array}$ \\
\hline
\end{tabular}

Fonte: Elaborado pelo autor com base em Câmara Brasileira Do Livro, [2017].

Para alcançar os objetivos do estudo, dividimos o trabalho em duas partes, distribuídas da seguinte forma: a primeira abordará uma descrição mais detalhada do Prêmio Jabuti, buscando apontar a sua história e a concepção e identificar seus critérios de escolha, principais objetivos, e o seu funcionamento quanto principal prêmio da literatura brasileira. Já a segunda, dará enfoque no perfil dos autores contemplados em primeira colocação pelo Prêmio Jabuti, na categoria Romance, no período 2000 a 2016.

\section{Prêmio Jabuti}

Nos mais de 50 anos de edições do Prêmio, esse passou por diversas mudanças no que se refere ao formato, ao regulamento de obras inscritas para as premiações, à curadoria e a categorias abrangidas nos processos avaliativos. Estes incluem tanto profissionais especializados nas áreas de premiação, quanto aqueles que atuam nos mercados editoriais e que consumem as produções. As transformações também se devem ao número de obras participantes e de autores interessados em obter o Prêmio Jabuti. A prova disso são os acréscimos de obras inscritas para cada avaliação e, também, a seriedade, que segundo o site oficial do Prêmio salienta, prevaleceu durante toda a história do Prêmio: "manteve sua transparência, forte característica de seu regulamento, reconhecido por todos que produzem informação, conhecimento e arte no Brasil" (CÂMARA BRASILEIRA DO LIVRO, [2017]).

À frente do Jabuti esteve, no período de $2014 \mathrm{a}$ 2016, Marisa Lajolo, doutora em Literatura e uma das principais referências em pesquisa sobre leitura no Brasil. Juntamente com ela estão Antônio Carlos de Moraes Sartini, Frederico Barbosa, Luis Carlos de Menezes e Pedro Almeida que, em conjunto, organizam o processo de inscrição e avaliação de obras.

Em entrevista realizada pelo canal do YouTube "Conexão Universitária", publicado no site do Prêmio, Marisa Lajolo afirma ter sido dela a ideia de incluir na lista de categorias a de livro digital e livro infantil digital, afirmando que ainda consistem em categorias que têm muito a crescer. Esta é, portanto, uma das alterações que o Prêmio sofreu nos últimos anos.

Em sua $58^{a}$ edição, no ano de 2016, ocorreram muitas modificações, conforme aponta o site do Prêmio. A primeira delas foi a mudança no local da cerimônia de entrega dos prêmios, que era realizada na sede da CBL. A partir de 2004 e 2005 a premiação passou a ser no Memorial da América Latina, em São Paulo. Nos anos posteriores, até 2014, a Sala São Paulo foi o palco do Prêmio Jabuti e, desde então, é no auditório Ibirapuera, também em São Paulo, que as cerimônias vêm acontecendo.

Outra transformação significativa foi o aumento no número de categorias, pois no seu primeiro regimento constam apenas as categorias: literatura, capa e ilustração, editor do ano, gráfico do ano, livreiro do ano e personalidade literária. Atualmente, esse número triplicou e, há 27 categorias, que são divididas 
de modo mais claro a partir de temáticas e gêneros. São elas: Adaptação, Arquitetura e Urbanismo, Biografia, Capa, Ciências da Natureza, Meio Ambiente e Matemática, Ciências da Saúde, Ciências Humanas, Comunicação, Contos e Crônicas, Didático e Paradidático, Direito, Economia, Administração, Negócios, Turismo, Hotelaria e Lazer, Educação e Pedagogia, Engenharias, Tecnologias e Informática, Gastronomia, Ilustração, Ilustração de Livro Infantil ou Juvenil, Infantil, Juvenil, Poesia, Projeto Gráfico, Psicologia, Psicanálise e Comportamento, Reportagem e Documentário, Romance, Teoria/Crítica Literária, Dicionários e Gramáticas, Tradução. Em 2016, foi incluída a categoria Infantil Digital, que consiste na premiação de livros digitais infantis destinados para o público infantil.

Cada uma dessas divisões concorre a primeiro, segundo e terceiro lugar, sendo que a premiação para ambos é de um troféu e apenas o primeiro lugar ganha um total equivalente a R 3 mil . Trata-se de um valor simbólico, pois as pessoas que se inscrevem buscam mais precisamente o troféu, que representa reconhecimento e valorização tanto dentro como fora do Brasil. Pelo menos é nesse sentido que afirma Cristovão Tezza, que obteve $01^{\circ}$ lugar do Prêmio Jabuti em 2008 com o romance O Filho Eterno, publicado pela editora Record, em depoimento no site do Prêmio Jabuti:

Fui finalista algumas vezes do prêmio Jabuti. Em 2004, fiquei em terceiro lugar com o romance "O fotógrafo", e no ano passado levei o Jabuti de melhor romance com "O filho eterno". É simplesmente impressionante a repercussão que esse prêmio tem, a partir do fato de que é o mais antigo e todo mundo conhece. O Jabuti é uma instituição bastante "popular", o que é sempre surpreendente no mundo do livro brasileiro. Além do mais, ele repercute também na imprensa, o que multiplica a visibilidade da obra. Para mim, teve um efeito positivo, não só no Brasil mas também no exterior - o fato de ter ganho o Jabuti é um toque a mais a valorizar o livro e eventualmente abrir caminho para as traduções (CÂMARA BRASILEIRA DO LIVRO, [2009]).
Conforme aponta o autor, ganhar o Prêmio Jabuti é uma forma de valorização em relação a sua obra, além disso é uma maneira de abrir novas portas, tendo em vista que se trata de uma das maiores premiações brasileiras existentes no País. Além disso, é mostrar ao público que, dentre as milhares de obras, aquela chamou a atenção e foi considerada a melhor. Também traz a visibilidade do autor, que é reconhecido e agraciado pela imprensa tanto no Brasil como no exterior.

Além dessas várias categorias que concorrem a premiações, também estão em disputa o Livro do Ano de Ficção e o Livro do Ano de Não Ficção. É interessante destacar que, nas categorias maiores, quem julga o livro vencedor é uma equipe de jurados qualificada, já no livro do Ano de Ficção e Não Ficção, a equipe editorial também pode opinar e votar para a eleição. Conforme consta a explicação publicada no site principal do evento, na aba "História":

O Jabuti trouxe curiosidades sobre a premiação. Em 2004, por exemplo, o vencedor do Livro do Ano de Ficção foi Budapeste, de Chico Buarque. A obra, no entanto, ganhou Menção Honrosa $\left(3^{\circ}\right.$ lugar) na categoria Romance. No dia seguinte, a mídia impressa abriu espaço nas suas páginas para questionar o episódio. Como um livro que ficou em terceiro lugar na sua categoria poderia levar o prêmio de Melhor Livro do Ano? "O que ocorreu, na verdade, foi que os vencedores das 20 categorias são escolhidos somente pelos jurados e os Livros do Ano recebem também os votos do mercado editorial, sendo que o grande vencedor não necessariamente é o $1^{\circ}$ colocado de uma categoria”, explicou José Luiz Goldfarb, curador do Prêmio de 1991 a 2013 (CÂMARA BRASILEIRA DO LIVRO, [2017]).

Conforme é possível observar, após comentários vinculados na mídia sobre os critérios de avaliação da premiação, o responsável pelo Prêmio na época precisou esclarecer de que maneira eram feitos os critérios de avaliação. Conforme consta nos comentários acima, o processo de seleção é composto por profissionais altamente qualificados nas áreas de cada modalidade, que leem e fazem as análises das obras. 
Em seguida, há uma cerimônia aberta ao público para a escolha das dez melhores obras de cada modalidade. Depois, em um próximo encontro, são escolhidas as três colocações. Para finalizar é realizada uma cerimônia de premiação, onde são contemplados os ganhadores dos três primeiros lugares e ainda os livros escolhidos como Livros do Ano de Ficção e Não Ficção, conforme aponta o site do Prêmio Jabuti.

Outro fator que merece destaque é que, ganhar o Prêmio Jabuti é uma importante referência para saber quais obras são avaliadas positivamente pela crítica, ou seja, há uma maior visibilidade para essas obras e autores que, de certo modo, são consagrados com essa premiação importante no âmbito da literatura brasileira. Conforme aponta Zilberman (2017), existem três benefícios importantes tanto para o autor da obra quando para o receptor de uma obra premiada: primeiro, estímulo de desenvolvimento para uma literatura nacional; segundo, divulgação das obras do escritor, seguido de um estimulo financeiro; e terceiro, visibilidade nas editoras cujas obras foram publicadas.

Outro ponto a se considerar refere-se ao fato de que, mesmo que haja um rol de avaliadores com knowhow e experiência na área, toda a avaliação precede um juízo de valor, que é também subjetivo e baseado em critérios individuais. O que para um jurado pode ser uma grande obra, para outro pode não ser. Não há como mensurar nem resolver essa questão. Nessa perspectiva, por mais que a premiação seja singular, sempre vai exteriorizar um julgamento de um grupo desconhecido, cujos critérios de avaliação o público desconhece.

Em relação à sua premiação, ela acontece da seguinte forma, conforme aponta a página do Prêmio: cada categoria recebe o valor de $\mathrm{R} \$ 3.500$ e uma estatueta representante do Prêmio nas primeiras colocações, já os segundos e terceiros lugares recebem apenas o troféu. Além desses prêmios, o Jabuti também contempla o Livro do Ano de Ficção e o Livro do Ano de Não Ficção. Nessa concorrência os ganhadores recebem uma estatueta dourada, representante do Prêmio, e o valor de R \$ 35 mil.

Para concorrer a essa premiação, o candidato precisa ser editor, escritor, tradutor, ilustrador, produtor gráfico ou designer, preencher uma ficha de inscrição que fica disponível no site do evento e, em seguida, fazer o pagamento do boleto, referente à taxa de inscrição e encaminhar cinco exemplares. Os valores para a inscrição variam, e podem ser observados a seguir, conforme consta no Guia de Orientação do Prêmio Jabuti ${ }^{4}$, disponível no site do evento:

No caso de obra individual, os valores por obra e categoria na qual a mesma for inscrita são: $\mathrm{R} \$ 270,00$ (duzentos e setenta reais) para Associados da CBL;

$\mathrm{R} \$ 350,00$ (trezentos e cinquenta reais) para Associados de Entidades Congêneres; $\mathrm{R} \$ 410,00$ (quatrocentos e dez reais) para Não Associados.

No caso de coleção, os valores por coleção e categoria na qual for inscrita são:

$\mathrm{R} \$ 420,00$ (quatrocentos e vinte reais) para Associados da CBL;

$\mathrm{R} \$ 450,00$ (quatrocentos e cinquenta reais) para Associados de Entidades Congêneres;

$\mathrm{R} \$ 490,00$ (quatrocentos e noventa reais) para Não Associados.

Desconto progressivo para grupo de inscrições: De 10 a 30 Inscrições - 5\% de desconto sobre o valor total

De 31 a 60 Inscrições - 10\% de desconto sobre o valor total

De 61 a 100 Inscrições - 15\% de desconto sobre o valor total

Acima de 100 Inscrições $-20 \%$ de desconto sobre o valor total (CÂMARA BRASILEIRA DO LIVRO, [2017]).

Como é possível visualizar, embora o valor de inscrição seja acessível, é preciso considerar que há um quantitativo elevado de inscrições, o que garante uma receita para o ganhador. Porém, além do bônus

4 Link para acesso ao guia de orientação: http://premiojabuti.com.br/wp-content/uploads/2016/09/58-jabuti-guia-de-orientacao-jurados-v2_1.pdf. Acesso em: 30 fev. 2017. 
financeiro, ele é contemplado especialmente no sentido de obter maior visibilidade a sua produção.

De acordo com Mariana Passos Ramalhete Guerra (2015), os descontos progressivos são o aspecto que mais chama a atenção dos autores, pois, se uma editora, por exemplo, submeter um grande número de livros para análise, além de conseguir diminuir o valor da inscrição, ainda tem a chance de pelo menos uma de suas obras ser contemplada, resultando, assim, no reconhecimento também para a editora. Conforme aponta a autora, esse pode ser um caminho a ser seguido pelos autores e editoras, pois ambos podem ganhar: o autor com o reconhecimento e a editora com a grande procura da obra, que é a consequência da premiação.

O júri que irá avaliar essas obras nas 27 categorias é composto por três jurados, especializadas na categoria que irão avaliar; cada jurado deve desconhecer a identidade dos seus companheiros de avaliação; após avaliar cada obra, devem classificá-la com uma nota entre 8 e 10, enviando em envelope lacrado para a CBL. Em audiência pública, os envelopes são reunidos e abertos. Só ocorre alteração no nome do vencedor se este estiver falecido, então ele é encaminhado para a seção in memoriam e recebe somente a estatueta. O próximo candidato, então, é nomeado como vencedor e ganha a estatueta e o valor financeiro conforme exposto no regulamento.

$\mathrm{Na}$ sua proposta, o Jabuti apresenta um regulamento, que explicita que as categorias e as obras são analisadas, porém, quando se remete a quem as analisa e quais fatores são relacionados, o que se sabe é apenas que quem as analisa são profissionais da área de cada categoria. Mas, que profissionais são esses? Só é sabido quem julgou no momento da divulgação dos vencedores. Por um lado, essa omissão deixa dúvidas, pois o crítico que for julgar irá conhecer o autor da obra e pode levar em consideração aspectos pessoais e trajetórias de produção escrita, por exemplo, no momento do julgamento.

Há também uma certa falta de clareza sobre os critérios de avaliação utilizados pelos jurados, pelo menos para quem busca compreender a concepção do programa. Na categoria Romance, que é o objeto de análise deste trabalho, consta que o jurado precisa estipular uma nota de 8 a 10 nos quesitos: 1) Técnica narrativa; 2) Constituição das personagens; e 3) Originalidade. Parecem-nos critérios bastante amplos, que não dão conta de todos elementos de um romance e que possibilitam uma análise bastante subjetiva, muito alicerçada nas leituras e concepções de quem avalia as obras. Logo, podemos pensar que, se os critérios são assim amplos e subjetivos, como as premiações podem de fato legitimar uma obra? Isso porque parte daquelas que são destaque são avaliadas por profissionais do mercado editorial. Não estariam estes profissionais muito mais preocupados com as vendas de determinado produto e menos com a qualidade, originalidade e técnica que uma obra pode oferecer?

Mesmo assim, nesse contexto, o Prêmio Jabuti é considerado uma referência, pois sua abrangência quanto ao número de categorias avaliadas é muito maior do que os prêmios já referidos neste estudo. Enquanto a maioria analisa e avalia apenas um ou dois gêneros, o Jabuti vai muito além e trabalha ainda com diferentes áreas do conhecimento, como é o caso da arquitetura, matemática, ciências da natureza e da saúde, por exemplo. Então, além de trazer vários gêneros literários, sua abrangência é muito maior, indo além do texto escrito e se adentrando na própria confecção de um livro, ou seja, aspectos importantes de uma obra que também precisam ser levados em conta no momento da leitura.

Um quesito importante no Jabuti é que ele, com o passar dos anos, vai se atualizando. Em 2015, por exemplo, uma nova categoria foi lançada, a Infantil Digital, tendo em vista que estamos cada vez mais inseridos em uma era digital, o Prêmio achou viável saber os tipos de textos que estão sendo escritos de modo digital. Dessa forma, será avaliado o conteúdo digital de cada livro, os elementos multimídias dispostos na ferramenta, além de links interativos e hipertextuais. Incluir essa categoria é uma forma de valorização de quem produz esse tipo de narrativa digital, além disso é de mostrar que existem conteúdos bons e que merecem destaque no âmbito da literatura não canônica.

Como já mencionado no início desse trabalho, o Jabuti é considerado um dos mais reconhecidos e 
comprometidos prêmios do Brasil, pois, além de se pautar e valorizar somente obras brasileiras, o seu foco está em diferentes áreas do conhecimento. Ou seja, sua abrangência é bem maior do que os demais, o que o faz ser mais procurado pelos escritores, sem contar que cada uma de suas categorias possui primeiro, segundo e terceiro lugar, sendo assim mais um fator pela grande procura.

Outro ponto negativo que recai em relação aos outros prêmios é a premiação: enquanto a maioria aposta em um grande valor em dinheiro, ele traz o reconhecimento em primeiro lugar, pois os ganhadores das categorias normais recebem apenas um valor simbólico, esse valor só aumenta um pouco ao contemplar os Livros de Ficção e Não Ficção. A premiação em dinheiro serve como um incentivo a mais na carreira de um autor, ainda mais se este está ainda iniciando sua vida editorial. No entanto, o que se percebe no Jabuti é que o maior valor parece ser o reconhecimento por parte de quem ganha, pois, além de ser conhecido no Brasil, ainda tem a possibilidade de alçar uma carreira internacional pelo prestígio e grande conceito que um escritor premiado pode ter.

\section{Perfil dos autores contemplados pelo Jabuti - categoria Romance}

O Prêmio Jabuti, durante o século XXI, consagrou diversas obras tanto literárias como não literárias. Muitos autores foram contemplados, reconhecidos e, devido à premiação, obtiveram prestígio no meio social e acadêmico. Mas, quem são esses autores? O que fazem? De onde vêm? Que obras já produziram? Conforme já mencionamos na introdução, este ensaio busca analisar o perfil de autores contemplados nas primeiras colocações da categoria Romance do Prêmio Jabuti, considerando apenas as edições do século XXI, que compreendem os anos 2000 a 2016.

Nesses dezessete anos, três autores se repetem como vencedores: Moacyr Scliar, Milton Hatoum e Bernardo Carvalho, sendo o primeiro premiado nos anos 2000 e 2009, o segundo em 2001 e 2006 e o terceiro em 2004 e 2014. São estes os autores restantes, totalizam o número dezessete, assim divididos: Rubens Figueiredo; Ana Miranda; Nélida Piñon; Eliane Brum; Cristovão Tezza; Edney Silvestre; José Castello; Oscar Nakasato; Evandro Affonso Ferreira; Maria Valéria Rezende; Julián Fuks.

Constatamos que dos 14 autores que obtiveram o primeiro lugar na categoria Romance do Prêmio, seis deles têm menos de dez obras literárias publicadas, conforme aponta o quadro a seguir, que mostra o número de obras publicadas por cada autor, divididas em literárias e não literárias.

\section{Quadro 2 - Número de obras ${ }^{5}$}

\begin{tabular}{|c|c|c|c|}
\hline AUTOR & $\begin{array}{c}\text { TOTAL DE } \\
\text { OBRAS }\end{array}$ & $\begin{array}{c}\text { OBRAS } \\
\text { LITERÁRIAS }\end{array}$ & $\begin{array}{l}\text { OBRAS NÃO } \\
\text { LITERÁRIAS }\end{array}$ \\
\hline Moacyr Scliar & 134 & 113 & 21 \\
\hline Milton Hatoum & 05 & 05 & 0 \\
\hline $\begin{array}{c}\text { Rubens } \\
\text { Figueiredo }\end{array}$ & 08 & 08 & o \\
\hline Ana Miranda & 29 & 28 & 01 \\
\hline $\begin{array}{l}\text { Bernardo de } \\
\text { Carvalho }\end{array}$ & 12 & 12 & o \\
\hline Nélida Piñon & 21 & 21 & 0 \\
\hline Eliane Brum & 06 & 05 & 01 \\
\hline $\begin{array}{c}\text { Cristovão } \\
\text { Tezza }\end{array}$ & 22 & 17 & 04 \\
\hline $\begin{array}{l}\text { Edney } \\
\text { Silvestre }\end{array}$ & 11 & 07 & 04 \\
\hline $\begin{array}{c}\text { Oscar } \\
\text { Nakasato }\end{array}$ & 02 & 01 & 01 \\
\hline $\begin{array}{l}\text { Evandro } \\
\text { Affonso } \\
\text { Ferreira }\end{array}$ & 10 & 10 & o \\
\hline $\begin{array}{l}\text { Bernardo } \\
\text { Carvalho }\end{array}$ & 12 & 12 & o \\
\hline $\begin{array}{c}\text { Maria Valéria } \\
\text { Rezende }\end{array}$ & 17 & 17 & o \\
\hline Julián Fuks & 04 & 04 & 0 \\
\hline
\end{tabular}

Fonte: Elaborado pelo autor com base em dados da Câmara Brasileira do Livro, [2017].

O autor Moacyr Scliar é quem lidera o ranking com o maior número de obras publicadas no meio impresso, chegando a somar em torno de 100 obras,

5 Tabela elaborada em janeiro de 2017, sendo que a principal fonte de pesquisa fora o site Wikipédia. Para efeito de contagem, são consideradas obras apenas livros. 
além das traduzidas para outros idiomas como o inglês, o espanhol, o francês e o alemão. Isso faz com que o autor seja reconhecido não só nacionalmente, mas também em âmbito internacional. A sua produção pode ser vista como um reflexo do reconhecimento que adquiriu perante os seus leitores e também pelo fato de escrever não só obras literárias, mas ainda livros voltados para a Medicina, sua área de formação, para a qual se dedicou de forma concomitante à carreira literária.

Seguido de Scliar, vem Ana Miranda, com cerca de 60 obras publicadas. Vários fatores podem levar um autor a aumentar sua produção literária impressa, mas para Ana Miranda supõe-se que o fato de ter tido seu romance Desmundo publicado em 1996, adaptado para o cinema, fez com que não só leitores, mas também expectadores conhecessem a autora e uma de suas obras. Esse fator também gera reconhecimento perante o público e pode motivar os escritores a produzirem mais obras para alcançar uma massa de leitores e fazer parte do hall de obras e autores considerados canônicos. Suposições essas que podem ou não responder a esses questionamentos.

Os demais autores têm poucas obras, apesar de nenhum deles ser estreante na literatura e na produção impressa ou digital em geral. A experiência em elaboração textual pode ser um dos fatores facilitadores para o sucesso deles no concurso, já que a produção na literatura pode se constituir em um desdobramento da escrita, com imersão em outros gêneros, e uma ampliação dos horizontes (inclusive profissionais) como produtores de texto.

$\mathrm{O}$ fato de os romances premiados serem produzidos, na maioria, por escritores que não têm significativa produção literária (em termos quantitativos) parece assinalar que o Prêmio está promovendo um movimento interessante: o de oportunizar que novas vozes autorais tenham possibilidade de serem reconhecidas e desfrutar do prestígio que o Prêmio traz; o de incitar uma renovação de autores no rol daqueles que são considerados de "qualidade literária" no cenário da literatura brasileira recente.

Muitos desses autores e obras ainda são pouco estudados e conhecidos pela crítica brasileira, pois, em vários casos, trata-se de autores que há pouco tempo adentraram na produção literária e, desse modo, ainda possuem poucas obras publicadas. Esse dado se comprova a partir de uma pesquisa no Banco de Teses e Dissertações da CAPES na qual, utilizando como palavra-chave o nome dos autores e analisando os 100 primeiros resultados, percebemos que, sobre as obras literárias de alguns deles, não há muitos trabalhos em teses e dissertações. É o caso de Oscar Nakasato e Julián Fuks, que são referenciados somente em suas próprias dissertações de Mestrado e teses de Doutorado e, ainda, Edney Silvestre, que não possui nenhum trabalho sobre suas obras. É o que mostramos no quadro a seguir.

\section{Quadro 3 - Pesquisa no Portal da CAPES}

\begin{tabular}{|c|c|}
\hline AUTOR & NÚMERO DE TRABALOS \\
\hline Moacyr Scliar & 38 \\
\hline Milton Hatoum & 82 \\
\hline Rubens Figueiredo & 03 \\
\hline Ana Miranda & 24 \\
\hline Bernardo de Carvalho & 22 \\
\hline Nélida Piñon & 32 \\
\hline Eliane Brum & 04 \\
\hline Cristovão Tezza & 14 \\
\hline Edney Silvestre & 0 \\
\hline Oscar Nakasato & $0^{6}$ \\
\hline Evandro Affonso Ferreira & 01 \\
\hline Maria Valéria Rezende & 01 \\
\hline Julián Fuks & $0^{7}$ \\
\hline
\end{tabular}

Fonte: Elaborado pelo autor com base nos dados pesquisados no Banco de Teses e Dissertações da CAPES 8 .

\footnotetext{
${ }^{6}$ Os únicos trabalhos que constam desse autor são sua Dissertação do Mestrado e Tese do Doutorado.

7 Os únicos trabalhos que constam desse autor são sua Dissertação do Mestrado e Tese do Doutorado.

${ }_{8}$ Os dados expostos no quadro foram preenchidos com base em pesquisa realizada no Banco de Teses e Dissertações da CAPES em março de 2017.
} 
Dos quatorze autores estudados, como mostra o gráfico 1, a seguir, constatamos que a maioria deles vêm do Sudeste (cinco são do Rio de Janeiro, um é de Minas Gerais e dois são de São Paulo). Autores nordestinos, do Norte e do Centro-Oeste são os menos contemplados pelo Prêmio. O Sul está representado por quatro autores, sendo um de Santa Catarina, dois do Rio Grande do Sul e um do Paraná.

\section{Gráfico 1 - Naturalidade dos autores}

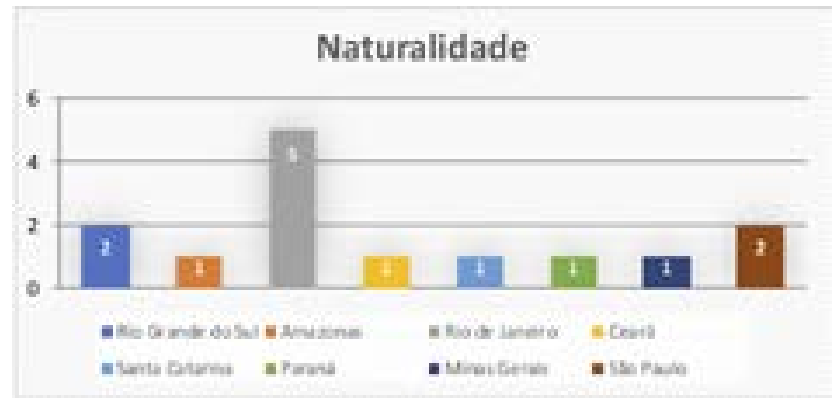

Fonte: Elaborado pelo autor com base em pesquisas bibliográficas acerca das biografias dos autores

Tais dados indicam que, possivelmente, há uma projeção maior de autores do Sudeste talvez em função de facilidade de acesso a editoras e meios de divulgação literária, de leitores nessas regiões, de trabalhos de pesquisa na área. Enfim, hipóteses que podem tentar explicar isso, mas não determinar. Não há como prová-las. Porém, poderíamos pensar por quais outras razões as obras de escritores do Centro-Oeste não aparecem na premiação. Seria apenas porque não se produz ou porque, havendo produção, não são merecedoras do Prêmio ou esse estaria ignorando o que se faz fora do eixo Sul-Sudeste?

No rol de autores consagrados nas edições do século XXI do Prêmio, há um claro predomínio de voz masculina, em contraste com o da feminina, pois dos 14 nomes, apenas quatro são de mulheres. Isso consolida um dado interessante: continua havendo um apagamento da autoria feminina no sentido de se constatar uma maior visibilidade da escrita de homens. Isso ocorre apesar de a avaliação das obras não ser totalmente identificada, uma vez que, no formulário de avaliação dos romances que concor- rem ao Prêmio, o regulamento traz três questões em cada categoria para o avaliador se embasar, sendo elas, na categoria Romance: 1) Técnica narrativa; 2) Constituição dos personagens; e 3) Originalidade.

Considerando que o Prêmio Jabuti é uma referência importante para identificar autores representativos na produção romanesca, podemos afirmar que ele dá continuidade a um processo recorrente de nossa historiografia literária: o de privilegiar romances escritos por homens mesmo que, nos diversos períodos de produção, composições de mulheres também existissem. O movimento desses referenciais é o de ignorar o que a escrita feminina traz, uma vez que as obras de autoras não são contempladas em abordagens analíticas em proporção similar a de escritas masculinas.

Os dados acerca da questão de gênero dos autores ratificam também a ideia, sublimar na nossa historiografia, de que mulheres escrevem pouco se comparado com o número de obras compostas por homens. Ainda buscam fazer acreditar que as mulheres, ao produzirem literatura, apresentam obras de qualidade questionável ou menos singulares, o que justificaria a ausência delas em livros dessa natureza e em premiações tão significativas como a do Jabuti.

O leitor menos atento, pouco preocupado em discutir as escolhas da premiação, pode não chegar a essas constatações, porém os questionamentos são importantes para se refletir sobre o "cânone" romanesco que o Jabuti está propondo e quais são as implicações que essas seleções apresentam. Não há como ignorar que o ocultamento da produção de mulheres na premiação analisada forma um "cânone" de autoria predominante masculina, ratificando um perfil conservador no que tange à narrativa romanesca brasileira

Refletindo sobre o perfil dos autores dos romances agraciados com o Jabuti, identificamos que as formações acadêmicas de cada autor variam, pois são de diferentes áreas, no entanto é possível visualizar que prevalecem as graduações e Letras e Jornalismo, como mostra o gráfico 2. 


\section{Gráfico 2 - Formação}

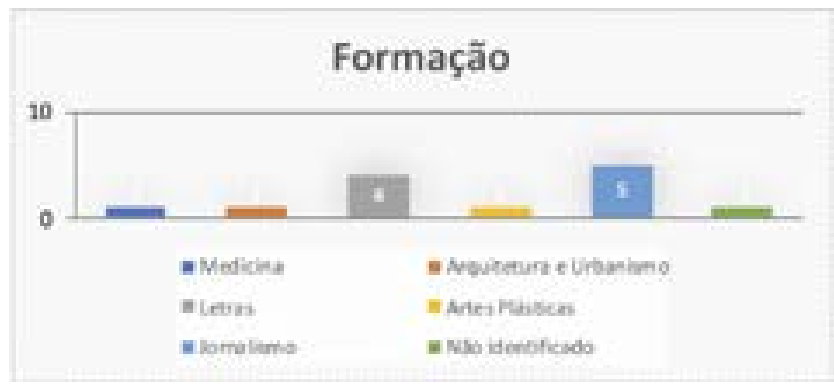

Fonte: Elaborado pelo autor com base em pesquisas acerca da biografia dos autores

A variedade de formação dos escritores se dá, pelo menos em parte, pela intimidade desses profissionais com as letras, o que de um modo geral pode favorecer a qualidade literária dos romances. Além disso, a formação na área das letras e jornalismo indica um novo perfil de escritores prestigiados, recusando-se a ideia de dom para escrever e valorizando a premissa de que trabalho, dedicação e artifício estético são fundamentais para escrever bem. Considerando esse contexto, parece que, para se ter prestígio como escritor de romance, é preciso ter técnica de escrever e não apenas uma boa história para contar. É, então, a valorização da profissionalização do escritor de literatura.

Em relação à profissionalização de escritores de literatura, Regina Zilberman (2010) traça um panorama sobre o desafio de o escritor conseguir se manter financeiramente com sua produção literária. Primeiro ela afirma que, desde 1897, a Academia Brasileira de Letras representa a reivindicação de que a profissão de escritor deva ser tratada como a de um sujeito qualquer e ainda que é preciso haver uma desconstrução da imagem do escritor como boêmio e desocupado.

Porém, não é sempre que um autor consegue se manter somente com a sua produção, aspectos como a falta de reconhecimento, a condição financeira desfavorável, o pouco público leitor, ou até a má aceitação da sua obra perante a sociedade são alguns dos fatores que podem levar um escritor a não conseguir permanecer somente no meio editorial. Zilberman (2010) ainda afirma ser através da grande venda de sua obra e de uma premiação literária um dos modos de se adentrar definitivamente no meio editorial. Ela ainda cita o exemplo do escritor Cristovão Tezza, que após vencer o Jabuti em 2008 com seu romance O filho eterno, pode largar seu emprego de professor universitário e se dedicar somente a sua escrita.

Além disso, ainda é possível constatar sob esse aspecto uma elitização da produção literária na medida em que quem alcança esse status não está escrevendo a primeira obra romanesca nem está fora dos bancos de formação no ensino superior. Pelo contrário, quem teve acesso à formação universitária

(e provavelmente leu muitos textos, incluindo os de literatura), está localizado em regiões brasileiras que facilitam a interação (eixo Rio-São Paulo) e está, ainda, familiarizado com as letras de uma forma geral.

Em relação à idade dos autores, considerando-se o ano de 2016 como ponto de referência para as análises, verificamos que o grupo dos 14 romancistas premiados no século XXI é de autores com maior experiência de vida, já que prevalecem os veteranos, com idades a partir dos 50 anos. Com esses dados é possível visualizar que autores jovens não aparecem nesse quadro, pois nenhum dos premiados possui idade abaixo de 30 anos. Uma hipótese para essa constatação é a possível falta de experiência e uma possível bagagem menor de conhecimentos e vivências podem influenciar na qualidade dos textos e, por isso, um menor destaque no Prêmio.

Em relação à etnia dos autores, a maioria dos escritores são brancos e nenhum negro aparece na lista. Essa afirmação vem ao encontro de uma pesquisa realizada por Regina Dalcastagnè na Universidade de Brasília, conforme a autora aponta em seu artigo "Um território contestado: literatura brasileira contemporânea e as novas vozes sociais" no qual ela faz um levantamento em um período de 15 anos (1990 a 2004) em todos os romances publicados por editoras importantes como a Companhia das Letras, Rocco e Record e constata que 93,9\% dos autores são brancos. Essa afirmação ainda continua prevalecendo no meio literário, pois não há nenhum indígena ou negro nessa lista de premiados do Jabuti. 
A pesquisa feita por Dancastagnè também retrata que, além desses autores serem, em sua maioria, brancos, ainda possuem uma boa formação acadêmica e 60\% desses vivem no Rio de Janeiro e São Paulo, ou seja, prevalece o velho estereótipo de que, se a pessoa possui uma graduação, um bom emprego, é branco e ainda vive em um grande centro urbano, já basta para ser um bom autor e até mesmo conquistar uma premiação literária.

Assim, ao se fazer um balanço dos autores contemplados nas edições do século XXI do Prêmio na categoria Romance, podemos fazer algumas inferências. Primeiro, o Prêmio Jabuti traz inovações no sentido de reconhecer autores mais jovens, ainda menos representativos no cenário literário e alguns "quase" iniciantes como escritores de literatura. Nessa perspectiva, participar de uma premiação literária seja ela apenas de âmbito regional é uma forma de alavancar a carreira, estimulando talentos promissores, aponta Zilberman (2010). Acreditamos que autores mais novos têm o privilégio de mostrar seus trabalhos e até adquirir um maior reconhecimento a partir da premiação, e desse modo servem-se de exemplos para a próxima geração ou até para aquele escritor que ainda não adquiriu um público leitor de suas obras.

Segundo, dá vazão a escritores que, além de terem familiaridade com as letras de uma forma geral, têm contato com mídias e associações, podendo assim publicar textos no meio digital, participar de entrevistas, dialogar com leitores e principalmente alavancar a sua carreira através da divulgação da sua obra. Além disso, a premiação pode impulsionar a participação deles em palestras, como mediador, por exemplo, em qualquer lugar do país ou do mundo, o que ocasiona um contato maior com seus (possíveis) leitores.

Terceiro, o Prêmio segue um padrão intelectual específico, gerando reconhecimento. A maioria dos escritores contemplados nas edições analisadas dispõe de condições financeiras favoráveis e de uma formação acadêmica (mestrado e doutorado inclusive) com experiências de estudo fora do País. Esse cenário justifica o que Dalcastagnè (2012) afirma ao dizer que esses autores contemplados são privilegiados por possuírem boas profissões e ainda dominarem o discurso, já que se encontram, em sua grande maioria, no meio jornalístico e acadêmico, desse modo já possuem o hábito e o dom da escrita, pois estudaram para aperfeiçoá-la.

Reconhecer a receptividade de uma obra literária é muito importante para saber como esta vem sendo vista perante a crítica literária, pois é através desse fator que muitos autores recebem um maior destaque diante do seu modo de escrever. Esse destaque pode ser bom ou não, pois tudo irá depender da maneira como o crítico literário analisa determinada obra. É através dessa receptividade também que muitos autores acabam abrangendo um maior público e se tornando conhecidos no meio acadêmico.

Em relação ao número de prêmios já recebidos pelos autores premiados no século XXI pelo Jabuti, mais uma vez é Scliar é quem lidera o ranking. Ele conta com um vasto número de premiações literárias, como mostra o gráfico 2.

\section{Gráfico 2 - Número de premiações adquiridas por cada autor}

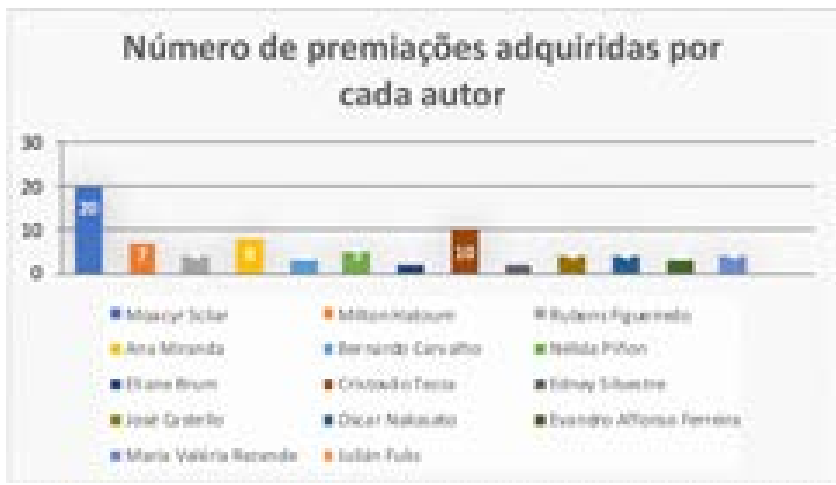

Fonte: Elaborado pelo autor com base em pesquisas acerca de premiações recebidas pelos autores

Scliar destaca-se nas premiações por razões diversas, entre as quais a sua vasta produção literária e não literária ao longo de várias décadas e o seu perfil de autor, considerando representativo na literatura brasileira. Scliar segue o parâmetro tradicional de escritor cultuado pela historiografia literária: é branco, possui boas condições socioeconômicas de vida, vem de um grande centro urbano e possui uma 
formação acadêmica (graduação em Medicina) que também lhe confere status social.

Em relação aos concursos literários brasileiros nos quais participaram os escritores estudados, cabe destacar que o Prêmio Jabuti é o mais procurado pelos autores em função de sua ampla abrangência e seu reconhecimento tanto dentro como fora do Brasil. Sobre o Jabuti, Tania Rösing (2016) afirma que, além de despertar uma grande curiosidade para saber quem serão os vencedores, ainda é divulgado o conjunto de obras editadas pelo autor, fator quede certo modo amplia suas vendas.

Dentre os gêneros literários mais explorados pelos autores premiados pelo Jabuti em primeira colocação no século XXI, o romance é o que se sobressai:

\section{Gráfico 3 - Gêneros Literários mais explorados}

\section{Gêneros Literários mais explorados}

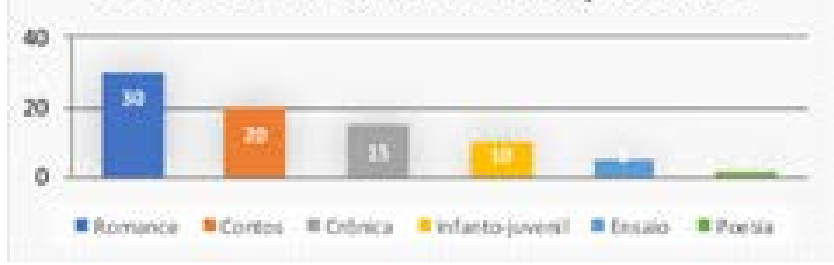

Fonte: Elaborado pelo autor com base em pesquisas acerca da produção literária dos autores

O romance é o gênero literário mais explorado, pois se trata de uma obra com uma estrutura mais completa comparando com o conto. Nela é possível a introdução de mais personagens, cenários, enredos, conforme afirma Dalcastagnè “[...] no romance, podemos vislumbrar personagens mais inteiras - ou seja, com maior desenvolvimento" (DALCASTAGNÈ, 2012, p. 150). Desse modo, o romance talvez seja o mais usado por ele, por proporcionar ao autor um maior "espaço" para criar a sua narrativa. Além disso, os autores parecem buscar uma sustentação nesse gênero como forma de especialização na produção literária.

\section{Considerações finais}

Partindo-se do pressuposto de que "A importância dos prêmios literários não é medida apenas pelo ângulo da criação e circulação de obras e seus autores. Prêmios literários também sinalizam tendências, e talvez constituam um termômetro bastante adequado para se medir o estado atual de uma literatura" (ZILBERMAN, 2017, p. 425), ainda podemos ressaltar que o Prêmio Jabuti, no recorte temporal analisado (2000-2016), é um importante instrumento de divulgação literária. Em tempos de crise da literatura e de leitores cada vez menos adeptos ao texto literário, é salutar a sobrevivência de uma premiação como a do Jabuti. Ela contribui para que a literatura seja mais amplamente divulgada em noticiários, reportagens e programas televisivos e em canais da internet nos quais se comentam as obras premiadas ou congregam a presença dos próprios autores. Sob esse prisma, o Prêmio tem uma função social: trazer ao público a literatura, especialmente a que é recentemente publicada, mostrando aos leitores e espectadores que o texto literário continua sendo uma produção viva em nossa cultura.

Quanto ao enfoque dado aos romances consagrados, algumas observações são importantes no sentido de se pensar numa leitura, mesmo que parcial, das tendências que a premiação sinaliza quanto ao perfil de autores romanescos consagrados. Dessa forma, o Prêmio Jabuti aponta para uma tendência que revela pelo menos três traços singulares: é conservadora, porque parece continuar a privilegiar tendências romanescas já consagradas em séculos anteriores, sem ocupar-se em valorizar o que a literatura recente traz de inovação temática e estética.

A premiação também valoriza a literatura masculina, pois a maioria dos romances premiados é escrito por homens, o que pode fazer supor, numa leitura mais superficial, que homens escrevem mais e melhor do que mulheres ou que estas pouco escrevem, justificativas que poderiam explicar a supremacia de nomes masculinos na lista de premiados. Nesse sentido, o Prêmio dá continuidade ao que vemos na historiografia literária ratificada em livros didáticos, por exemplo: um rol de obras de autoria masculina com omissão das produções de muitas escritoras, omitindo vozes femininas de nossas letras.

Por fim, a premiação revela um traço elitista em relação ao perfil de autores que consagra à medida 
que vemos nomes cujas histórias profissionais acenam para homens das letras, de formação universitária e do eixo centro-sul. Minorias étnico-raciais e sociais são pouco evidentes pelo menos quando se observam os escritores de romances - algo que também precisa ser visto como reforço do apagamento de vozes literárias das margens e como apreço ao que historicamente se rotulou como grande literatura.

\section{Referências}

CÂMARA BRASILEIRA DO LIVRO (Brasil). Governo Federal. Jabuti. 2017. Disponível em: https://www.premiojabuti.com.br. Acesso em: 3 jan. 2017.

CAPES. Banco de Teses e Dissertações. Disponível em: http://bancodeteses.capes.gov.br/banco-teses/\#!/. Acesso em: 22 mar. 2017. https://doi.org/10.29397/reciis.v11io.1397

DALCASTAGÈ, Regina. Literatura brasileira contemporânea: um território contestado. Vinhedo: Horizonte, 2012.

DALCASTAGÈ, Regina. Um território contestado: literatura brasileira contemporânea e as novas vozes sociais. Revista Iberic@1, Paris, n. 2, p.13-18, mar. 2012. Disponível em: http://iberical.paris-sorbonne.fr/wp-content/uploads/2012/03/002-02.pdf. Acesso em: 24 fev. 2017. https:// doi.org/10.18411/a-2017-023

GERRA, Mariana Passos Ramalhete. O leitor e a literatura juvenil: um diálogo entre os prêmios literários Jabuti e FNLIJ e o Programa Nacional Biblioteca da Escola. 2015. 156 p. Dissertação (Mestrado em Educação)-Universidade Federal do Espírito Santo, Centro de Educação, Vitória, 2015. Disponível em: file:///C:/Users/Emanoeli/ Downloads/tese 9361 Disserta\%C3\%A7\%C3\%A30\%20-\%20 Vers\%C3\%A30\%20Final\%20-\%20Mariana\%20Ramalhete\%20 (2).pdf. Acesso em: 6 abr. 2017. https://doi.org/10.5327/ Z1982-1247201500020011

LAJOLO, Marisa. Entrevista ao canal Conexão Universitária. Publicado por Câmara Brasileira do Livro, [S. l.: s. n.], 27 nov. 2018. Disponível em: https://www.premiojabuti.com. br. Acesso em: 20 jan. 2017.

PRÊMIO JABUTI. Disponível em: http://premiojabuti.com. br/. Acesso em: 30 out. 2016.

RÖSING, Tania Mariza Kuchenbecker. Produção literária contemporânea: divulgação, premiações, recepção entre leitores e leitores em formação. In: PEREIRA, Helena Bonito (org.) Ficção brasileira do século XXI: história, memória e identidade. São Paulo: Editora Mackenzie, 2016.

ZILBERMAN, Regina. Desafios da literatura brasileira na primeira década do séc. XXI. Revista Nonada, Porto Alegre, v. 02, n. 15, p. 183-200, 2010. Disponível em: http://seer.uniritter.edu.br/index.php/nonada/article/viewFile/276/189. Acesso em: 24 mar. 2017.
ZILBERMAN, Regina. O romance brasileiro contemporâneo conforme os prêmios literários (2010-2014). Revista de Estudos de literatura brasileira contemporânea, Brasília, n. 50, p. 424-443, jan./abr. 2017. Disponível em: file:///C:/ Users/Emanoeli/Downloads/Artigo\%20urgente\%20para\%20 leitura\%20-\%20Zilbeman\%202017\%20(1).pdf. Acesso em: 6 abr. 2017. https://doi.org/10.1590/2316-40185025

Recebido em: 16/6/2017.

Aprovado em: 8/5/2019.

\section{Ana Paula Teixeira Porto}

Universidade Regional Integrada do Alto Uruguai e das Missões (URI)

Orcid: http://orcid.org/0000-0002-2674-8020

E-mail: anapaulateixeiraporto@gmail.com

Endereço de correspondência: Avenida Melvins Jones, 1600, 452. Jardim Europa

Santa Cruz do Sul - RS. CEP 96 820-820

\section{Emanoeli Ballin Picolotto}

Universidade Regional Integrada do Alto Uruguai e das Missões (URI)

Orcid: https://orcid.org/0000-0003-0881-9347

E-mail: emanoeli.ballinp@hotmail.com

Endereço de correspondência: Avenida Melvins Jones, 1600, 452. Jardim Europa

Santa Cruz do Sul - RS. CEP 96 820-820 